\section{Sorologia de Malária Vivax no foco Aldeia dos Índios, Município de Peruíbe, Estado de São Paulo, 1984 a 1986 *.}

\author{
Maria Esther de Carvalho** \\ Carmen Moreno Glasser** \\ Ricardo M. de Carvalho Ciaravolo** \\ Arnaldo Etzel** \\ Lucilia A dos Santos** \\ Cláudio Santos Ferreira***
}

* Trabalho apresentado no $X$ Congresso da Sociedade Brasileira de Parasirologia, Salvador, $B A, 2$ a 6 de agosto de 1987 .

* Da Superintendência de Controle de Endemias - SUCEN da Secretaria de Estado da Saúde de São Paulo.

** DC Departamento de Parasitologia do Instituto de Ciências Biomédicas da Universidade de São Paulo.
Registraram-se, nos últimos vinte anos, casos autóctones de malária por Plasmodium vivax no Município de Peruíbe $\left(24,19^{\circ} \mathrm{S}\right.$ e $\left.47,00^{\circ} \mathrm{W}\right)$, Litoral Sul do Estado de São Paulo, com presença de portadores assintomáticos ou oligossintomáticos associada ou nāo a parasitemias subpatentes. $O$ problema na área é também con hecido como "bromélia-malária"; os vetores pertencem ao subgênero Kerteszia: Anopheles (K.) cruzii e A. (K.) bellator. A partir do segundo semestre de 1984 foram realizados, semestralmente, inquéritos sorológicos visando a dois objetivos: detectar possiveis fontes de infecçāo inaparente e obter o perfil sorológico da população, visando à melhoria do conhecimento da dinâmica da transmissão da malária e seu controle no foco. Este compreende 10 localidades, com população de cerca de 3000 pessoas, cuja mobilidade associa-se à presença de visitantes à aldeia indígena; à fazenda de cacau, que incorpora mâo-de-obra transitória; em casas de temporada e existência de grupos nos quais a rotatividade se dá em função do processo de posse da terra. Como atividade econômica destaca-se a agricultura de banana e de cacau, além dos cultivos de subsistência. A técnica sorológica utilizada - reação de imunofluorescência indireta (RIFI) - foi processada com antígenos de P. vivax. $O$ valor diagnóstico da RIFI foi confirmado pela identificação de alguns casos autóctones antes que as gotas espessas se revelassem positivas. A distribuição de freqüências de títulos na população foi comparável ao padrâo de área de baixa endemicidade. Os soro-positivos predominaram entre o sexo masculino e nos grupos etários acima de 15 anos, faixas a que pertencem os indivíduos produtivos Cadernos de Saúde Pública, RJ, 4 (3): 276-292, jul/set, 1988 
na agricultura e que apresentam uma relação mais estreita com a mata.

PALAVRAS-CHAVE: malária vivax soroepidemiologia.

\section{INTRODUÇÃO}

O município de Peruíbe, situado no Litoral Sul do Estado de São Paulo $\left(24,19^{\circ} \mathrm{S}\right.$ e $\left.47,00^{\circ} \mathrm{W}\right)$ tem apresentado, nos últimos vinte anos, casos autóctones de malária por Plasmodium vivax que se concentram, principalmente, em um foco denominado "Aldeia dos Indios". Em sua maior parte, os casos aí gerados se caracterizam como óligos ou assintomáticos, com baixas parasitemias detectáveis ou mesmo subpatentes (4). Tais peculiaridades são semelhantes às já observadas no Litoral do Estado de Santa Catarina por AveryJones \& Ferreira Neto (1). Da conhecida associação do ciclo biológico das espécies vetoras pertencentes ao subgênero Kerteszia: Anopheles $(K$.$) cruzii e A$. $(K$.) bellator, às bromélias, originou-se a denominação, para o problema, de "bromélia-malária" $(10)$.

A Superintendência de Controle de Endemias SUCEN - da Secretaria de Estado da Saúde de São Paulo desenvolve atividades de busca de casos humanos, seu tratamento radical e combate ao vetor por meios químicos (uso de inseticida Dicloro Difenil Tricloroetano - DDT - em ciclos semestrais). A partir do segundo semestre de 1984, foram realizados, entre os habitantes da região, inquéritos sorológicos tendose em vista dois objetivos principais: detectar possiveis fontes de infecção inaparente, pelo fato de ser admitida maior sensibilidade diagnóstica dessa técnica em relação à hemoscopia, no caso específico da área (Carvalho (3), 185) e estabelecer-se um perfil sorológico das populaçōes que constituem o objeto do estudo. Associado ao primeiro está a hipótese de corresponderem a reservatórios de parasitas os casos sorologicamente reagentes a títulos iguais ou superiores a 64; aceita essa hipótese, poderia um resultado situado dentro dessa faixa ser usado como critério para desencadear-se o tratamento radical, mesmo na vigência de hemoscopia negativa, como sugerido em trabalho de Warren \& cols. (15), 1975. Decorrentes do segundo objetivo, 
seriam obtidos subsídios de apoio para o conhecimento da dinâmica da transmissão da malária no foco.

PEDRO DE TOLEDO

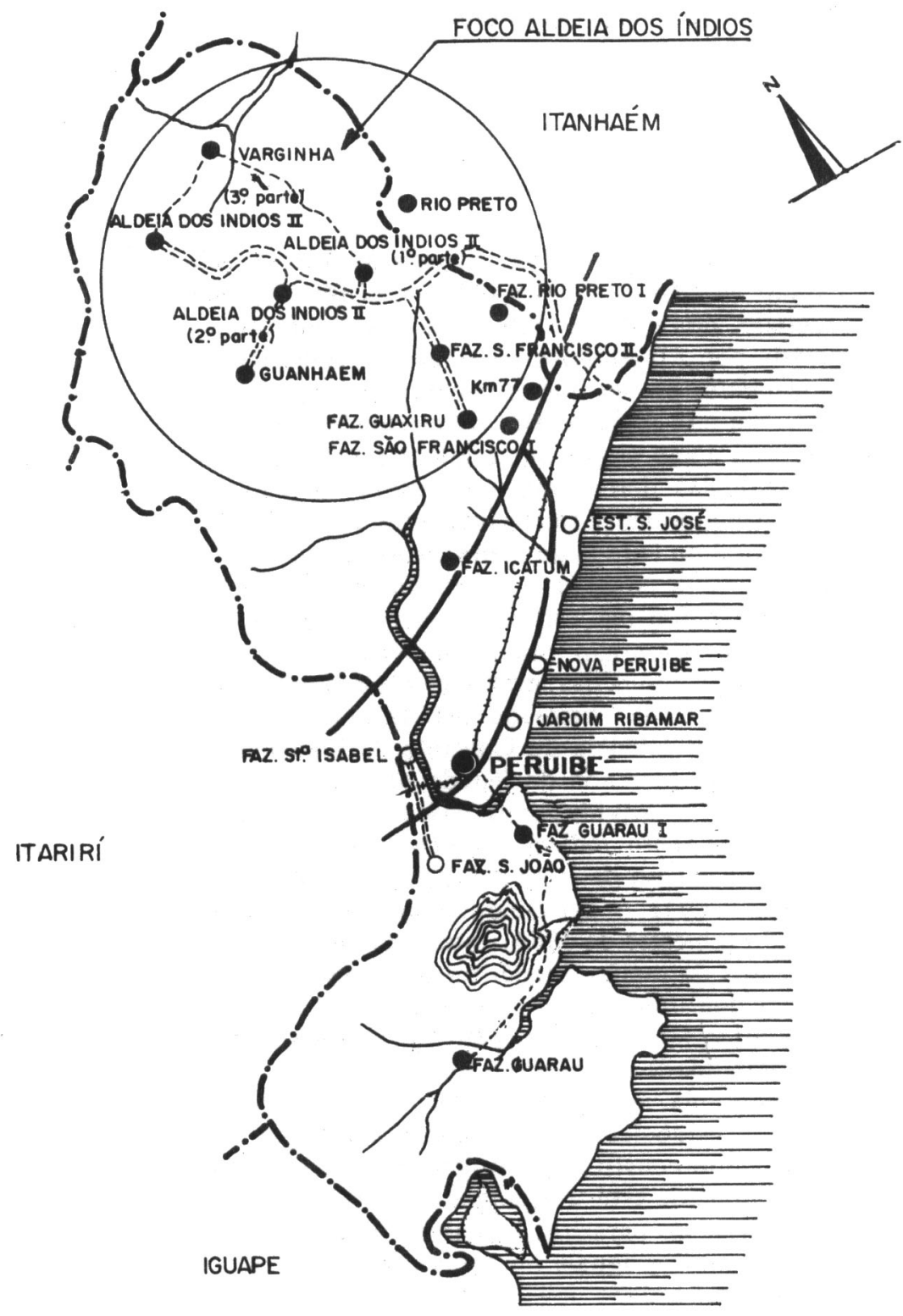

Fig. 1 Foco de malária vivax no município de Peruíbe, S.P. 


\section{Caracterização da Área}

$O$ foco Aldeia dos Índios inclui 10 localidades, dentre as quais uma pertencente ao município limítrofe de Itanhaém (Figura 1) e congrega uma população de cerca de 3000 habitantes. A população móvel está relacionada à existência de chácaras de recreação, presença de posseiros, turistas em visita à aldeia indígena e à Fazenda Caepupu (situada entre as localidades Aldeia dos Índios II - 2: parte e Fazenda Rio Preto de Itanhaém), uma das pioneiras na introdução do cultivo do cacau no Litoral Paulista e que incorpora importante rotatividade de mão-de-obra. Destaca-se, na área, como atividade econômica, a agricultura, predominando os cultivos de banana e cacau. Existem também os cultivos de subsistência de arroz, feijão etc., que ocupam área reduzida; em toda a paisagem predomina a vegetação silvestre. A escassa ocupação da terra, nesses locais, pode ser atribuída às suas características de riqueza em acidentes topográficos, devendo ser considerados estes como restritivos para o desmatamento.

Dentre as 10 localidades em observação, a Fazenda São Francisco I (assinalada fora do foco na Figura 1) situa-se na faixa de transição entre a planície litorânea e a região montanhosa. Nessa região não se observa, na paisagem, a predominância da mata, o que a destaca das outras que compóem o foco. Mobilidade considerável é observada na população que para lá se desloca, principalmente durante os fins de semana ou férias escolares; nessas ocasiões são ocupadas as numerosas casas destinadas a uso nas temporadas, chácaras e sítios espalhados por vasta área. $\mathrm{Na}$ Aldeia dos Índios II - 1: Parte, soma-se a esse tipo de movimentação aquela em torno da aldeia indígena aí existente (envolvendo funcionários da Fundação Nacional do Índio - FUNAI - e indígenas provenientes de outras regiōes). $\mathrm{Na}$ localidade de Varginha e em alguns trechos de regióes vizinhas há acentuada rotatividade da população (composta principalmente por homens), com flutuações decorrentes do processo de ocupação das terras.

\section{MATERIAL E MÉTODOS}

\section{Material}

Foram colhidas em suporte de papel-filtro "Whatman n: 3", 12604 amostras de sangue digital da popu- 
lação residente na área do foco e do controle, cuja distribuição por unidade de superfície foi avaliada, de acordo com as recomendaçōes de Ferreira \& Carvalho (9), 1982, correspondente a aproximadamente 15,2 microlitros de soro por $m$ de papel. Após dessecação, a temperatura ambiente, as amostras foram armazenadas, sob refrigeração, na Sede do Serviço Regional de São Vicente, da SUCEN, até o momento de sua remessa ao Laboratório, em São Paulo, onde foram processadas.

\section{Métodos}

19) Técnica sorológica - Foi utilizada a reação de imunofluorescência indireta (RIFI), de acordo com a técnica de Sulzer \& cols. (14), 1969, com antígeno preparado a partir de sangue venoso de pacientes infectados por $P$. vivax, cujas parasitemias estavam ao redor de 30.000 elementos por $\mathrm{m}$ de sangue. Foi tomada a precaução de separar-se a fração plasma logo após a colheita do sangue venoso, tendo em vista a eventual presença de anticorpos antiplasmódios que pudessem reagir $\mathrm{cm} o$ antígeno presente. Em lâminas para microscopia de fluorescência, tendo cada uma sua área de observação dividida em 20 quadrinhos, foi colocado o antígeno, fixado à temperatura de $37^{\circ} \mathrm{C}$ em estufa. As lâminas-antígeno assim resultantes foram embaladas em pacotes de cinco unidades cada. As operações mencionadas eram executadas de acordo com as recomendaçōes da Organização Panamericana da Saúde (13), 1975, para estocagem de lâminas com gotas espessas de sangue em congelador à temperatura de $22^{\circ} \mathrm{C}$ negativos. No momento do uso, eram "desemoglobinizadas" por meio de água destilada.

Foi adotada a técnica de processamento simultâneo de pares de amostras (Carvalho \& cols. (6), 1985), pelo fato de haver conhecimento prévio da baixa prevalência de malária na região de onde eram provenientes as amostras. Desse modo, o intervalo de tempo entre a colheita das amostras e a entrega dos resultados era abreviada. As amostras que se revelavam reagentes na triagem (diluição a 1:16) eram submetidas à RIFI quantitativa.

Os conjugados utilizados foram obtidos comercialmente, sendo seus títulos determinados no Laboratório, sempre em termos de máxima reatividade (Camargo (2), 1973).

2:) Inquéritos - A área delimitada pelo foco, dentro 
de um raio de cerca de $5 \mathrm{~km}$, abrangeu 9 localidades do município de Peruibe assim denominadas: Varginha, Aldeia dos Índios II - Parte A ou Aldeia dos Indios II - 1: Parte, Aldeia dos Índios II - Parte B ou Aldeia dos Índios II - 2: Parte, Aldeia dos Índios II - Parte C ou Aldeia dos Índios II - 3: Parte, Guanhaém, Fazenda Rio Preto I, Fazenda São Francisco II e Fazenda Guaxiru; do município limítrofe Itanhaém, a localidade Rio Preto (Figura 1).

Foram realizados cinco inquéritos, com periodicidade semestral, a partir do 2 : semestre de 1984 , nos meses de fevereiro - março e agosto - setembro. Como área-testemunha foi selecionada a compreendida por duas localidades periféricas de Peruíbe, sem transmissão demonstrada de malária: Caraguava e Caraminguava.

Teve-se como objetivo coletar amostras de sangue de toda a população presente, tendo sido para isso feito um trabalho a cargo da equipe de Educaçáo Sanitária que contou, durante o primeiro inquérito, com a colaboração voluntária de alunas do magistério de Peruíbe.

Os resultados foram distribuídos segundo freqüências de títulos, por grupo etário e sexo. Utilizando-se como dados de entrada a idade, o sexo e o título sorológico, foram estes tabulados com o auxílio de microcomputador. Pra esse fim elaborou-se um programa em linguagem BASIC (4).

A população foi agrupada nas faixas etárias: de zero a 1 ano; de 2 a 5 anos (idade pré-escolar); de 6 a 9 anos (idade escolar); de 10 a 14 anos (idade escolar com participação na economia da família); de 15 a 39 e de 40 a 69 anos (faixas em que predominam os elementos economicamente ativos) e de idades superiores a 70 anos.

3:) Outras intervenções realizadas concomitantemente - Medidas de controle foram adotadas no foco (4), como borrifação das casas com inseticida (DDT) em ciclos semestrais e busca de casos, tanto ativa, mensal, de sintomáticos febris atuais ou recentes, quanto passiva, em que a própria população local procura os Postos de Notificação, visando ao diagnóstico. Além destas medidas, foram realizados inquéritos hemoscópicos semestrais coincidentes com os sorológicos.

\section{¿ESULTADOS}

A distribuição de freqüências de títulos das reações sorológicas realizadas nas amostras das populaCadernos de Saúde Pública, RJ, 4 (3): 276-292, jul/set, 1988 
Fig. 2

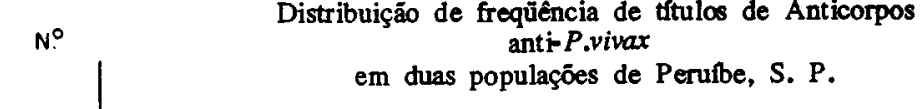

çōes-controle e do foco está representada na Figura 2; a linha que delimita os dois conjuntos de resultados (reagentes e não-reagentes) situa-se entre os títulos 16 e 32, corroborando o achado de outros autores, conforme referenciado em Carvalho (3), 1985. O gráfico obtido na área do foco foi compatível com o padrão de área de baixo nível de endemicidade (Kagan (11), 1973). A curva, neste caso, apresentou-se bimodal; há um grande número de reações negativas e, na região correspondente às positivas, um pico assinala a média geométrica em torno de 50. Assim, soros cujos títulos se situem em tomo dessa média ou acima representam os casos na população que estejam infectados ou mesmo que se tenham infectado recentemente ou ainda que tenham passado malárico.

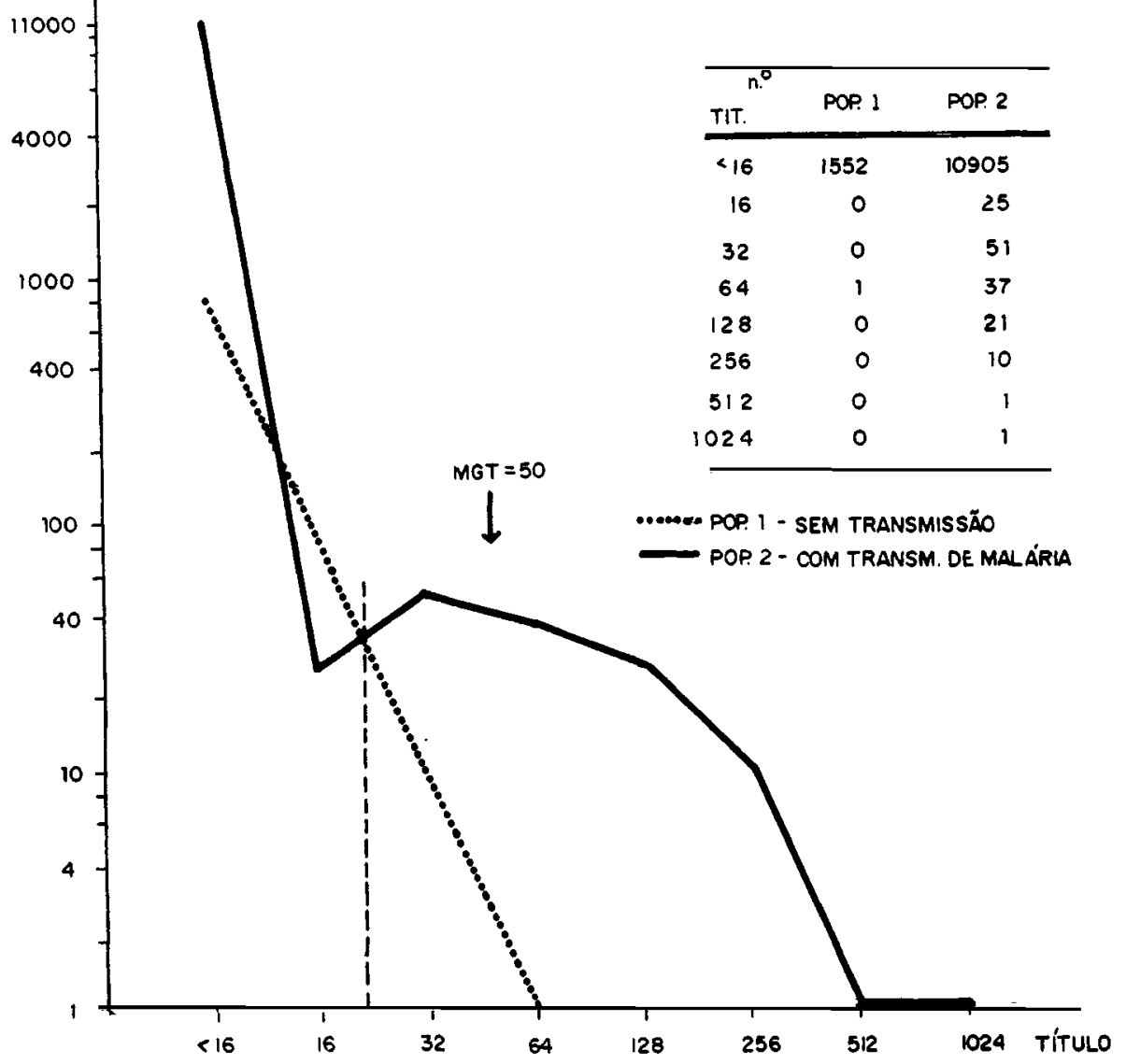


Durante a realização dos inquéritos, alguns casos de malária vivax autóctones foram detectados, na hemoscopia, ulteriormente à sorologia; os títulos observados nessas oportunidades situaram-se entre 64 e 512 (Carvalho e cols. (5), 1985), embora não seja possível associar-se título de reação sorológica à patência da parasitemia.

$\mathrm{Na}$ área utilizada como controle foram coletadas 1553 amostras, sendo 195 na localidade Caraminguava e 1358 na de Caraguava (Tabela 1). Na primeira, todos os resultados foram negativos; na segunda houve um único caso reagente que, ao ser investigado, relatou antecedentes de malária, sendo o local provável de transmissão a Aldeia dos Índios II - 3: Parte.

Os resultados da sorologia referentes ao foco, acumulados de 1984 a 1986 , são mostrados na Tabela 2. Observam-se nesta percentuais de positividade sempre maiores no sexo masculino do que no feminino (exceção no grupo de idade igual ou superior a 70 anos); as idades em que predominaram os casos reagentes situaram-se, em $97,3 \%$ dos casos, acima de 10 anos. Quando considerada a positividade acima da idade de 15 anos, faixa etária dos indivíduos economicamente ativos, dedicados principalmente à agricultura e que representa cerca de $60 \%$ da população total, esse percentual foi de 90,4 .

A transmissão de malária na área do foco tem-se mantido constante, não tendo ocorrido casos apenas em 1976 e 1981 (4). Neste ano foi realizado inquérito sorológico que revelou positividade de $1,26 \%$ (4). Em 1984 a positividade sorológica foi de $2,92 \%$, assumindo os seguintes valores nos anos subseqüentes: $0,36 \%$ e $1,17 \%$. Essa elevação da positividade sorológica em 1986 foi acompanhada do aumento de número de casos diagnosticados por hemoscopia no decorrer do mesmo ano (9 em 1985 e $16 \mathrm{em} \mathrm{1986).} \mathrm{A} \mathrm{queda} \mathrm{anteriormente}$ observada, tanto de número de casos hemoscópicos, que era 15 em 1984, quanto do percentual de positividade sorológica de 1984 para 1985 , pode ser atribuída parcialmente à adoção de uma nova intervenção no controle da malária, o tratamento radical de casos sorológicos cujos títulos fossem iguais ou superiores a 64. Mais recentemente, entretanto, observou-se o encontro de positivos hemoscópicos em casos sorológicos cujos títulos situaram-se abaixo do limite estabelecido para fins de tratamento, isto é, 16, o que nos leva a retomar a questão da hipótese de poderem ser reservatórios de parasitas, casos sob quaisquer títulos. 


\section{ARTIGO}

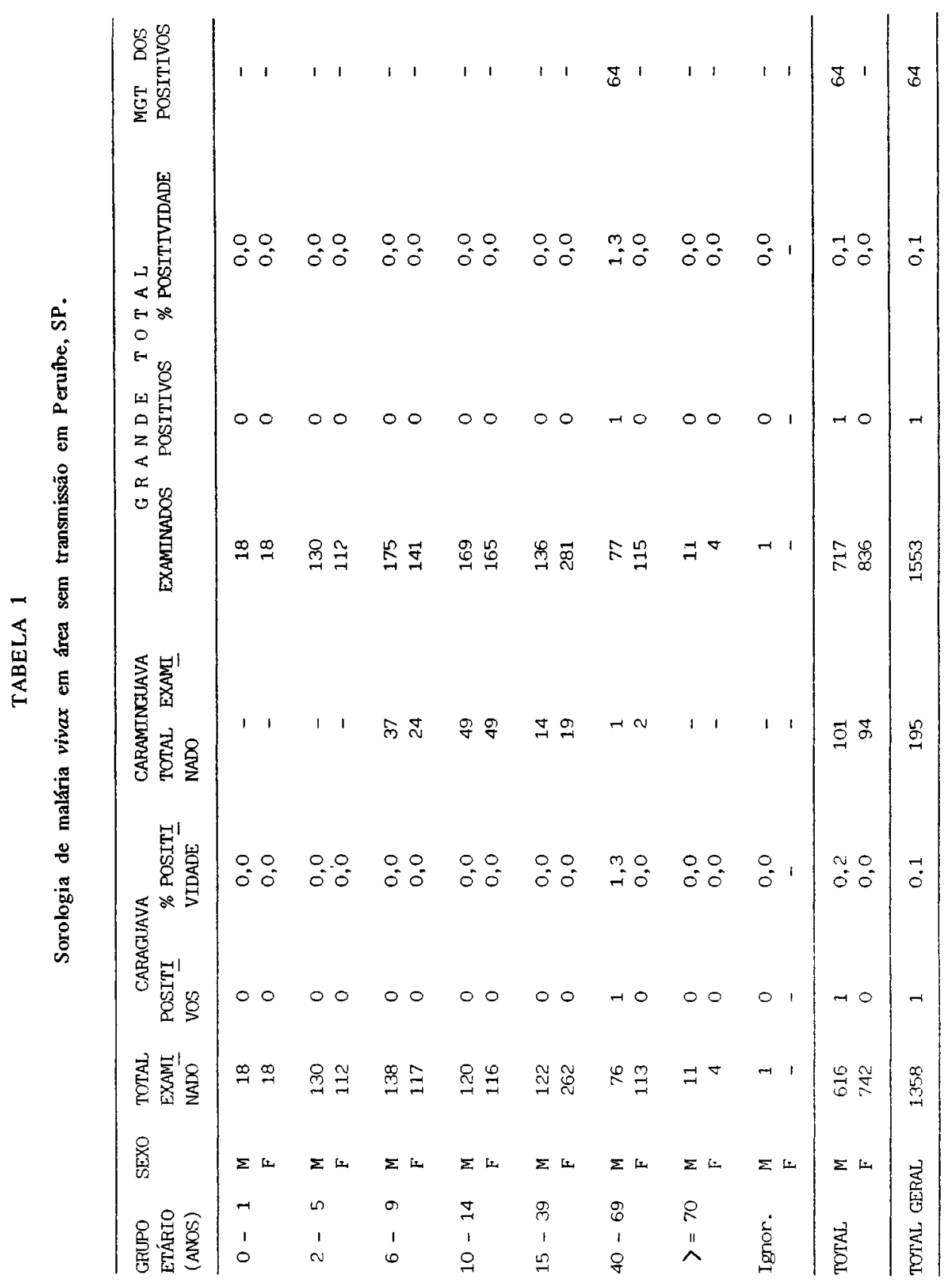


TABELA 2

Sorologia de malária vivax no foco Aldeia dos Índios, Perufbe, SP, 1984 a 1986

\begin{tabular}{|c|c|c|c|c|c|c|}
\hline $\begin{array}{l}\text { GRUPO } \\
\text { ETÁRIO }\end{array}$ & SEXO & $\begin{array}{l}\text { TOTAL } \\
\text { EXAMINADO }\end{array}$ & $\begin{array}{c}\% \\
\text { EXAM. }\end{array}$ & $\begin{array}{c}\text { TOTAL } \\
\text { POSITIVO }\end{array}$ & $\begin{array}{c}\% \\
\text { POSITIVO }\end{array}$ & $\begin{array}{l}\text { MGT DOS } \\
\text { POSITIVOS }\end{array}$ \\
\hline \multirow{2}{*}{$0-1$} & M & 126 & 1,14 & 0 & 0,00 & - \\
\hline & $F$ & 126 & 1,14 & 0 & 0,00 & - \\
\hline \multirow{2}{*}{$2-5$} & $M$ & 771 & 6,98 & 2 & 0,26 & 16,0 \\
\hline & F & 704 & 6,37 & 1 & 0,14 & 64,0 \\
\hline \multirow{2}{*}{$6-9$} & M & 689 & 6,23 & 1 & 0,14 & 64,0 \\
\hline & $F$ & 604 & 5,46 & 0 & 0,00 & - \\
\hline \multirow{2}{*}{$10-14$} & $M$ & 735 & 6,65 & 4 & 0,54 & 22,6 \\
\hline & $\mathbf{F}$ & 700 & 6,33 & 6 & 0,86 & 50,8 \\
\hline \multirow{2}{*}{$15-39$} & $M$ & 2260 & 20,45 & 50 & 2,21 & 58,4 \\
\hline & $F$ & 1770 & 16,02 & 25 & 1,41 & 48,5 \\
\hline \multirow{2}{*}{$40-69$} & M & 1521 & 13,76 & 44 & 2,89 & 47,4 \\
\hline & F & 883 & 7,99 & 6 & 0,68 & 90,5 \\
\hline \multirow{2}{*}{$\geqslant 70$} & $M$ & 101 & 0,91 & 4 & 3,96 & 53,8 \\
\hline & $F$ & 53 & 0,48 & 3 & 5,66 & 40,3 \\
\hline \multirow{2}{*}{ Ignor. } & $M$ & 3 & 0,03 & 0 & 0,00 & - \\
\hline & $F$ & 5 & 0,04 & 0 & 0,00 & - \\
\hline \multirow{3}{*}{ TOTAL } & M & 6206 & 56,16 & 105 & 1,69 & 50,4 \\
\hline & $F$ & 4845 & 43,84 & 41 & 0,85 & 53,1 \\
\hline & & 11051 & & 146 & 1,32 & 51,1 \\
\hline
\end{tabular}

Comparando-se os resultados obtidos no foco entre os casos detectados por hemoscopia segundo a técnica da gota espessa e por sorologia (Tabela 3 e Figura 3), observa-se que o predomínio da sorologia sobre a hemoscopia dá-se a partir das idades superiores a 14 anos na população masculina; na feminina, o único caso no grupo etário $2-5$ anos aparece na sorologia. A hemoscopia mantém-se negativa até o grupo $6-9$ anos. 
A proporção de casos masculinos em relação aos femininos, observada a partir do total geral da Tabela 3 foi de $0,825 / 0,175$ na hemoscopia e $0,719 / 0,281$ na sorologia. Quando aplicado a estes valores o teste da diferença de proporções (8), verifica-se que, aos níveis de $95 \%(\mathrm{z}=1,96)$ e de $99 \%(\mathrm{z}=2,58)$ de confiança, deve ser aceita a hipótese de não haver diferença entre as proporções.

TABELA 3

Casos de malária vivax diagnosticados por hemoscopia $(\mathrm{H})$ e por sorologia (S) no foco Aldeia dos fndios, Perume, SP.

\begin{tabular}{|c|c|c|c|c|c|c|c|c|c|}
\hline \multirow{2}{*}{$\begin{array}{l}\text { GRUPO } \\
\text { ETÁRIO } \\
\text { (ANOS) }\end{array}$} & \multirow[b]{2}{*}{ SEXO } & \multicolumn{2}{|c|}{1984} & \multicolumn{2}{|c|}{1985} & \multicolumn{2}{|c|}{1986} & \multicolumn{2}{|c|}{ TOTAL } \\
\hline & & $\mathrm{H}$ & $\mathrm{S}$ & $\mathrm{H}$ & $S$ & $\mathrm{H}$ & $S$ & $\mathrm{H}$ & S \\
\hline \multirow{2}{*}{$0-1$} & $\mathrm{M}$ & - & - & - & - & - & - & - & - \\
\hline & $F$ & - & - & - & - & - & - & - & - \\
\hline \multirow{2}{*}{$2-5$} & M & 2 & - & - & - & 1 & 2 & 3 & 2 \\
\hline & $F$ & - & - & - & 1 & - & - & - & 1 \\
\hline \multirow{2}{*}{$6-9$} & M & 1 & - & - & - & 1 & 1 & 2 & 1 \\
\hline & F & - & - & - & - & - & - & - & - \\
\hline \multirow{2}{*}{$10-14$} & M & 2 & 1 & - & 1 & 4 & 2 & 6 & 4 \\
\hline & $F$ & 1 & 5 & 2 & 1 & - & - & 3 & 6 \\
\hline \multirow{2}{*}{$15-39$} & M & 6 & 33 & 3 & 2 & 3 & 15 & 12 & 50 \\
\hline & $F$ & 1 & 15 & 2 & 1 & 1 & 9 & 4 & 25 \\
\hline \multirow{2}{*}{$40-69$} & M & 2 & 27 & 2 & 7 & 6 & 10 & 10 & 44 \\
\hline & $\mathrm{F}$ & - & 3 & - & 2 & - & 1 & - & 6 \\
\hline \multirow{2}{*}{$>=70$} & $\mathrm{M}$ & - & 2 & - & - & - & 2 & - & 4 \\
\hline & $F$ & - & 2 & - & 1 & - & - & - & 3 \\
\hline \multirow[b]{2}{*}{ TOTAL } & M & 13 & 63 & 5 & 10 & 15 & 32 & 33 & 105 \\
\hline & F & 2 & 25 & 4 & 6 & 1 & 10 & 7 & 41 \\
\hline $\begin{array}{l}\text { TOTAL } \\
\text { GERAL }\end{array}$ & & 15 & 88 & 9 & 16 & 16 & 42 & 40 & 146 \\
\hline
\end{tabular}




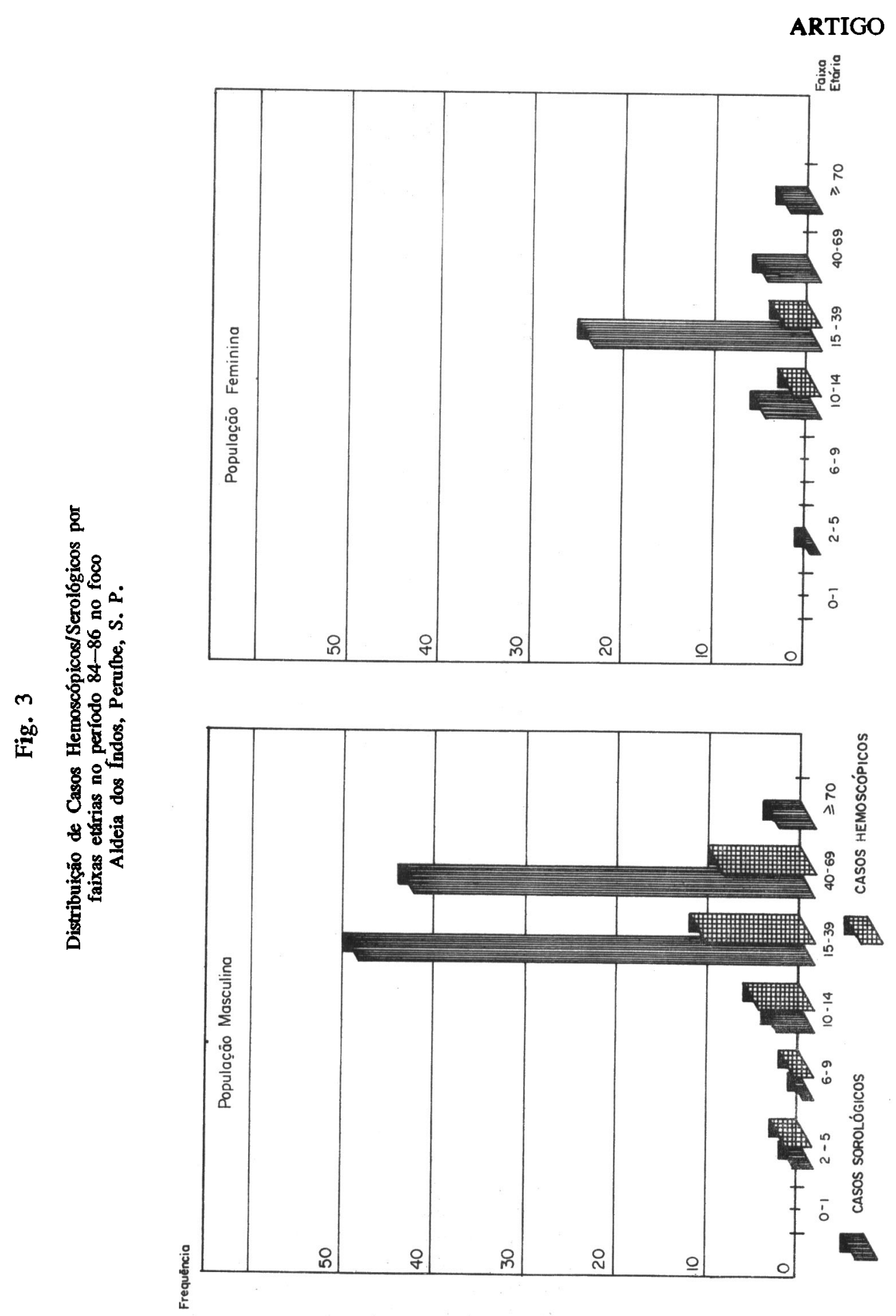




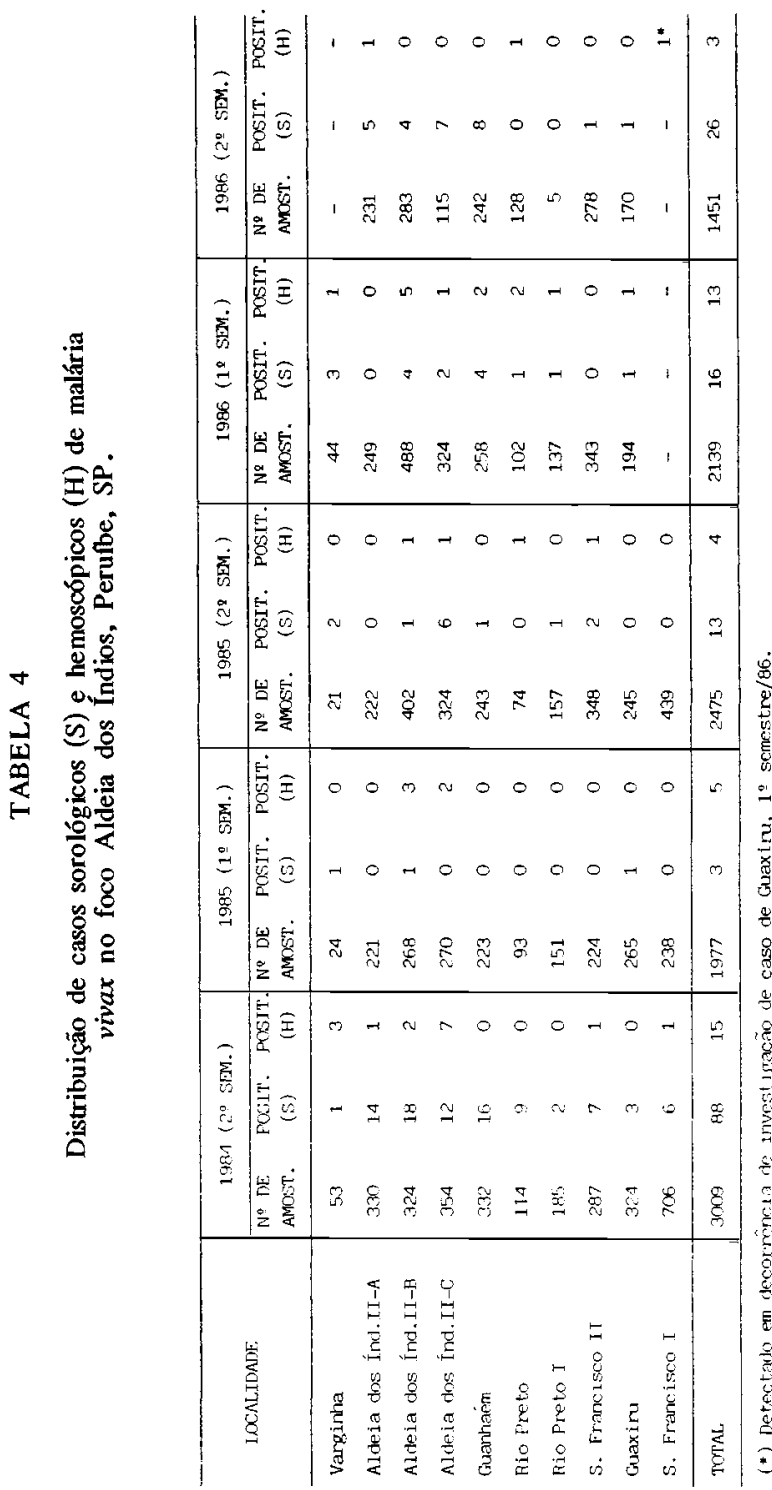

Em termos de cobertura, o primeiro inquérito foi o que contou com a maior participação da população (Tabela 4), atribuindo-se este fato à associação do rrabalho educativo especial organizado para a aplicaça do inquérito sorológico e a própria receptividade áa população ante o problema da malária existente na área. Em 1986 deixou-se de trabalhar uma das localidades (São Francisco I), situada além do raio de 
$5 \mathrm{~km}$ do centro do foco e que, no ano anterior, não gerara casos de malária. Finalmente, no segundo semestre de 1986 , por problemas de fixação de sangue no suporte de papel-filtro, por ação de calor, houve perda de considerável parte das amostras, o que fez reduzir a cobertura nessa ocasiaao.

Ainda com referência à Tabela 4 notamos a ocorrência de casos sorológicos centrada nas Aldeias e na localidade limítrofe, Guanhaém, fato também observado na distribuição dos casos hemoscópicos do foco.

\section{COMENTÁRIOS}

Tendo, entre outras, como finalidade, o aumento da sensibilidade diagnóstica, a metodologia sorológica pode revelar alguns casos ainda não detectados por meio da hemoscopia. Dadas as características da infecção malárica no foco em questão, dentre as quais se destaca a baixa parasitemia, o diagnóstico hemoscópico por meio da técnica de gota espessa foi aprimorado; aumentou-se o número de lâminas a examinar e, nos casos sorologicamente reagentes, os exames passaram a ser reiterados, buscando-se aumentar as probabilidades de verificar eventual existência de parasitemia. O emprego da associação sorologia/hemos copia passa a ser indicado nesses casos.

Emerge, em decorrência, a questão do tratamento radical dos casos sorológicos. Ainda que se desconheça com que probabilidade um infectado sorológico representa um reservatório de parasitas, não deve ser descartada essa hipótese, comprovada no foco. Entretanto, a abordagem do problema deve incluir, necessariamente, a verificação da permanência de anticorpos antiplasmódicos circulantes em dois subconjuntos da população: a) o dos casos constituídos por portadores de parasitemias patente, submetidos a tratamento radical para malária vivax e b) o dos reagentes sorológicos, sem demonstração de parasitemia, tratados, radicalmente ou não, com antimaláricos. Esse estudo deverá ampliar o acervo de informações relacionadas com o problema da interpretação dos títulos sorológicos, apontado por Meuwissen (12) como lacuna ainda persistente na literatura; salienta que deveriam ser feitos estudos sorológicos longitudinais para acompanhar a sua evolução, após tratamento radical dos casos. Esta é, portanto, uma das propostas do trabalho, já delineado, a desenvolver na área sob estudo.

A questão do título sorológico, antígeno-dependente, reacendeu a idéia aventada por Deane \& cols. 
(*) Dados ainda não publicados (do Laboratório de Sorologia da SUCEN) e consequientes ao trabalho "Inquérito hemoscópico e sorológico sobre malária em duas localidades do Estado de Rondônia", apresentado no XXIII Congresso da Sociedade Brasileira de Medici na Tropical, Curitiba, PR, 1987, de GR Y SCHEK, R. C. B.; SEGU: RADO, A. A. C.; DUTRA, A. P.; CARVALHO, M. E.;BRANQUINHO, M. S. \& BOULOS, M.
(7) ao desenvolver pesquisa em áreas de florestas no Litoral Norte do Estado de Santa Catarina, segundo a qual a dispersão vertical dos vetores comprova a probabilidade de que estes se alimentem tanto na copa das árvores quanto ao nível do solo. Assim, plasmódios sísmicos capazes de infectar o homem em condiçōes naturais poderiam estar sendo a ele transmitidos, estando presentes os necessários elos da cadeia. No foco Aldeia dos Índios tem sido observada a presença de macacos na área florestal. Surge, portanto a linha de pesquisa, a desenvolver, que consiste na verificação de níveis de anticorpos humanos antiplasmódios sísmicos. Para isso devem ser usados os antígenos correspondentes e os resultados comparados com os de reaçōes executadas com antígenos de plasmódios do homem. A experiência adquirida em áreas de endemicidade mais elevada quanto à malária, como os municípios de Ariquemes e Machadinho, Estado de Rondônia, nos quais a positividade sorológica situou-se, respectivamente, em redor de $25 \%$ e $45 \%$, mostrou que a média geométrica dos títulos sorológicos para $P$. vivax foi igual a 62,4 no primeiro e 73,4 no segundo caso $\left({ }^{*}\right)$. Esses resultados podem ser considerados como não discordantes dos observados no foco ora estudado, no qual foram utilizados antígenos de $P$. vivax preparados a partir de amostras de casos oriundos de zona de malária endêmica.

Não foram observados, nos cinco inquéritos realizados, alterações da média geométrica dos títulos e percentuais de positividade que demonstrassem alteraçōes na transmissão de malária no foco. Sabe-se que a interrupção da transmissão é acompanhada de queda da média geométrica dos títulos, mais rápida do que a dos percentuais de positividade (11). Os resultados indicaram apenas atividade focal, apresentando-se a informação sorológica consistente quando comparada à da hemoscopia. Assim, a persistência da transmissão de malária nessa região demonstrou a necessidade de ser adotada abordagem mais abrangente do problema do que a tradicionalmente usada. Seräo, portanto, propostos estudos de geografia humana visando-se a analisar, de modo mais profícuo, as condiçōes de instalação e manutenção do foco.

\section{AGRADECIMENTOS}

Os autores expressam seus agradecimentos às equipes de campo do Serviço Regional de São Vicente, da SUCEN; à Marcia Regina Delgado de Souza e Regina Yazawa, pelo apoio técnico no Laboratório

\footnotetext{
Cadernos de Saúde Pública, RJ, 4 (3): 276--292, jul/set, 1988
} 
de Sorologia e auxílio no processamento de dados sorológicos; à Maria José Nobre, pela datilografia do manuscrito e ao Romeu Angelo Tamelini, pelas ilustrações.

Cases of Plasmodium vivax malaria have been recorded in a region known as Aldeia dos Índios, Municipality of Peruibe $\left(24.19^{\circ} \mathrm{S}\right.$ and $\left.47.00^{\circ} \mathrm{W}\right)$, in the South Coastal Region of the State São Paulo, Brazil, for the last twenty years. Symptomless, parasitologically subpatent infections persist in that area. The vectors, Anopheles (Kerteszia) cruzii and $A$. $(K$.$) bellator breed on epiphytic Bromeliaceae, on$ the top of tall trees.

Serological surveys for malaria antibodies, by means of indirect immunofuorescence test, are being performes since the second half of the year 1984, to evaluate $P$. vivax antibody levels, and to identify possible sources of infection not detected by haemoscopy. Information is being put together to compose an adequate picture of dynamics of malaria transmission in that region, wich comprises ten localities with a total population of about 3,000. As economical activities predominate the cultivation of banana and cacao in addition to that for subsistence. Input data for microcomputer processing were age, sex, and titer. The results were associated to sex, age-groups and the geometric means of the serological titers. A low-endemicity frequency distribution pattern os serological titers was found in connection with the population studied. A predominance of serological cases in age-groups above 15 years was observed. In some cases, haemoscopic positivity was preceded by serological reactivity. The use of the combination haemoscopy/serology was accordingly indicated. Further investigation was proposed, such as a longitudinal study of haemoscopical and/or serological cases, submitted or not to radical treatment; a research on serological titers of the human population tested using as antigens simian plasmodia potentially infective to man, and an investigation on the installation and persistence of the focus from the viewpoint of human geography.

KEY-WORDS: vivax malaria - seroepidemiology. 


\section{REFERÊNCIAS BIBLIOGRÁFICAS}

1. AVERY-JONES, S. \& FERREIRA NETO, J. A. Symptomless Plasmodium vivax parasitaemias and malaria eradication in Santa Catarina State, Brazil. Geneva, World Health Organization, 1964. (WHO/M AL/64.469)

2. CAMARGO, M. E. Introduçāo às técnicas de imunofluorescência.São Paulo, Instituto de Medicina Tropical, 1973. p. 60-1.

3. CARVALHO, M. E. de Aspectos metodológicos e práticos da reação de imunofluorescência indireta aplicada à malária. Săo Paulo, 1985. (Dissertação de Mestrado. Departamento de Prática de Saúde Pública da Faculdade de Saúde Pública da Universidade de São Paulo) p. 19-20, 53-8.

4. CARVALHO, M. E. de \& GLASSER, C. M. Relatório de atividades em sorologia de malária vivax no foco Aldeia dos Índios, município de Peruibe, São Paulo. São Paulo, Superintendência de Controle de Endemias da Secretaria de Estado da Saúde, 1987.

5. CARVALHO, M. E. de; GLASSER, C. M.; SANTOS, L. A. dos \& CIARAvolo, R. M. DE C. Nota sobre o encontro de casos autóctones de malária vivax por meio de técnica sorológica em São Paulo. Cad. Saúde Púbi., $1: 250 \cdot 2,1985$.

6. CARVALHO, M. E. de; WANDERLEY, D. M. V.; CIARAVOLO, R. M. de C. \& FONSECA, J. A. B. da Soroepidemiologia de malária: aplicação da técnica de processamento simultâneo de pares de amostras. Hiléia Médica, 7:33-6, 1986.

7. DEANE, L. M.; FERREIRA NETO, J. A. \& LIMA, M. M. The vertical dispersion of Anopheles (Kerteszia) cruzii in a forest in Southern Brazil suggests human cases of malaria of simian origin might be expected. Mem. Inst. Cswaldo Cruz, 79:461-3, 1984 .

8. DIXON, W. J. \& MASSEY JR., F. J. Introduction to statistical analysis. 2nd ed. New York, McGraw-Hill Book Co., 1957. p. 232-4.

9. FERREIRA, C.S. \& CARVALHO, M. E. de Padronização de uso de papel-filtro como suporte de material para reaçóes sorológicas. Rev. bras. Malar., 34:82-6, 1982.

10. FORATTINI, O. P. Entomologia médica I São Paulo, Faculdade de Higiene e Saúde Pública, Departamento de Parasitologia, 1962. p. 554.

11. KAGAN, I. G. Parasitic diseases. In: Paul, J. R. \& White, C. Serological epidemiology. New York, Academic Press, 1973. p. $155-67$.

12. MEUWISSEN, J. H. E. TH. Introductory remarks on seroepidemiology and immunodiagnosis of malaria. Isr. J. Med. Sci., 14:687-9, 1978.

13. ORGANIZAÇĀO PAN-AMERICANA DA SAÚDE Manual de diagnóstico microscópico da malária. 2: ed. Washington, 1974 (Publicação Científica, n: 87) p. 74-8.

14. SULZER, A. J.; WILSON, M. \& HALL, E. C. Indirect fluorescent antibody tests for parasitic diseases. V. An evaluation of a thick-smear antigen in the IFA test for malaria antibodies, Amer. J. top. Med. Hyg., 18:199-205, 1969.

15. WARREN, McW.; COLLINS, W. E.; JEFFERY, G. M. \& SKINNER, J. C. The soroepidemiology of malaria in Middle America. II. Studies on the Pacific Coast of Costa Rica. Amer. J. trop. Med. Hyg., 24:749-54, 1975. 